\title{
New BDJ covers celebrate 100 years of the BDA Library
}

Volume 229 of the British Dental Journal, beginning with this issue (10 July), will look to celebrate 100 years of the British Dental Association (BDA) Library. Each cover of the $B D J$ will be produced by medical artist turned dental student Rachel Jackson, who was recently interviewed for the Journal. ${ }^{1}$

A survey was undertaken by the staff at the

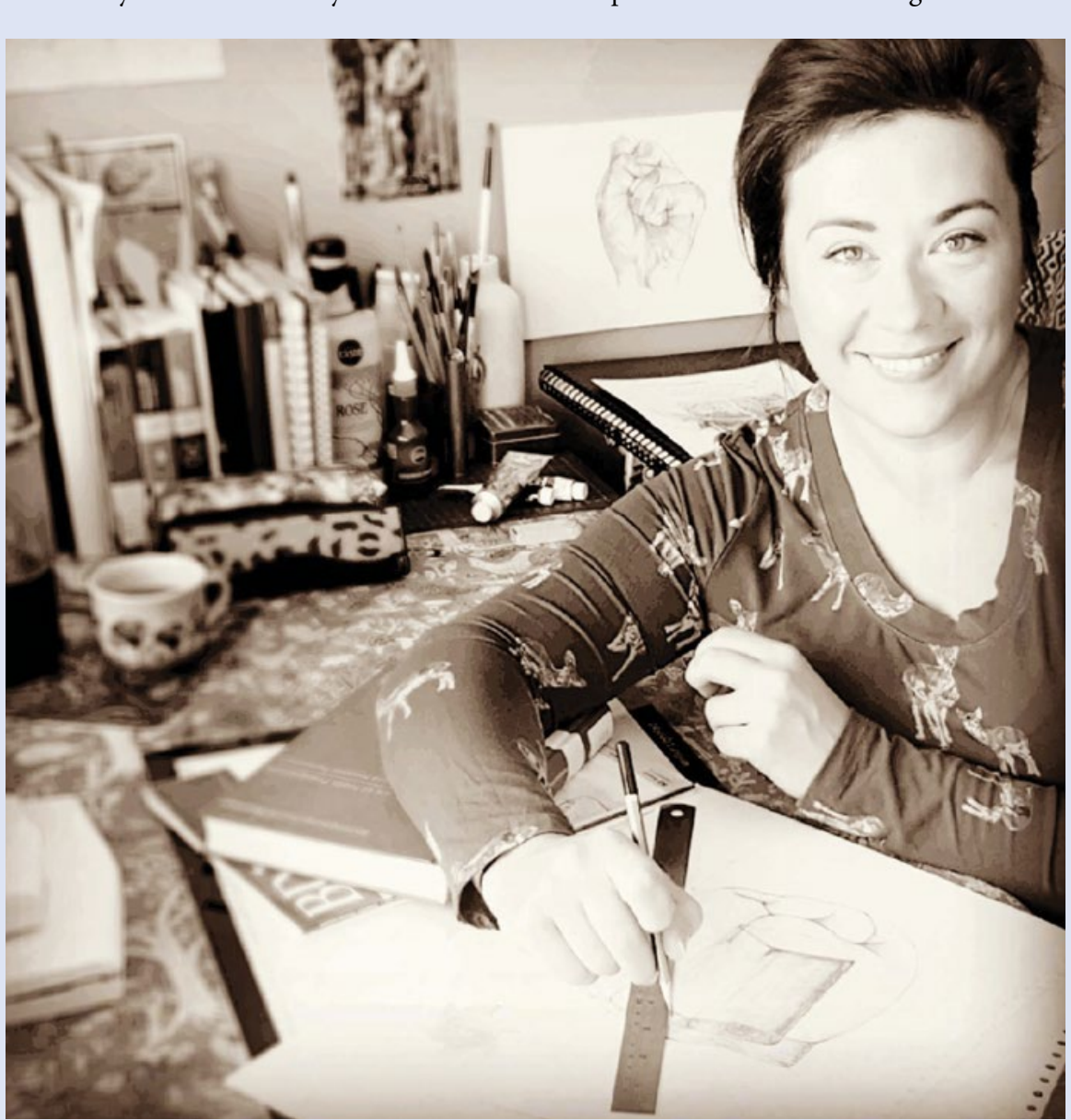

Medical artist and dental student Rachel Jackson

BDA Library to establish the most influential texts within dentistry over the past 100 years. Rachel will create original pieces of artwork that aim to convey the significance of each text. Each will be available to purchase at the end of the series with a percentage going to charity.

Rachel said: 'Ironically, isolation has resulted in the profession better connecting with each

\section{Young dentists create new online community}

A Facebook group called 'Deciduous' has been set up by young dentists during the COVID-19 lockdown as a means to establish a community amongst dental students and young dentists.

The group allows members to confide in each other and their experiences and mentor each other through the later stages of dental school and early career stages such as foundation or core training. The group's ethos is to create a welcoming, safe environment to express areas that they require more advice in - or indeed difficulties that they may face in

\section{the present or future.}

Members range from undergraduate dental students, hygiene/therapy trainees to graduated clinicians and specialists, all engaging in a closely monitored support network designed to give the answers to the questions dentistry might pose. In an unprecedented initiative during the lockdown the administrators organised and delivered mock VIVAs through teleconferencing. This was carried out through their own efforts and time during a period where the majority of people in the world were other now than I have ever known it to before. The backdrop of education in the form of webinars, discussion groups and a focus on wellbeing has facilitated this timely union'. Rachel would like to continue in this vein and connect the profession and the public by means of a blog series to accompany the cover production, which will be shared on the $B D \rho^{\prime}$ s social media platforms.

'The creative process sees me going down a myriad of tangents to make each piece symbolic and complements my aim to take a creative approach to science learning, said Rachel. 'Together we can celebrate the importance of dental literature and the library that has helped facilitate this over the years.'

In her blog, Rachel looks to include thoughts from the profession and will be releasing the name of the text beforehand for your input. 'I would like the profession to "inspire the artist" and give me their thoughts on the literature, how this has influenced their career and their memories as this all contributes to the final piece.'

First up is Fundamentals of fixed prosthodontics by $\mathrm{H}$. T. Shillingburg - an iconic book that is as relevant today as it ever was.

Rachel's blog can be found at www. medink.co.uk.

Reference

Quinlan K. Rachel Jackson: 'There is no more poignant time to consider art as therapy'. Br Dent J 2020; 228: 498-501. apprehensive about the effect of COVID-19 on everyday life. The mock VIVAs were delivered to final year dental students across the country and were a resounding success, resulting in over 150 dental students engaging in the process.

The group's goal is to become a hub for dental professionals to seek advice, promote learning and network collectively, making the transition between dental school and the real world simpler. https://www.facebook.com/ groups/1432306490280617. 